\title{
Combined Transcriptome Profiling Reveals a Novel Family of Arbuscular Mycorrhizal-Specific Medicago truncatula Lectin Genes
}

\author{
André Frenzel, ${ }^{1}$ Katja Manthey, ${ }^{2}$ Andreas M. Perlick, ${ }^{2}$ Folker Meyer, ${ }^{3}$ Alfred Pühler, ${ }^{2}$ Helge Küster, ${ }^{2}$ \\ and Franziska Krajinski ${ }^{1}$ \\ ${ }^{1}$ Lehrgebiet Molekulargenetik, Universität Hannover, Herrenhäuser Str. 2, D-30419 Hannover, Germany; ${ }^{2}$ Lehrstuhl für \\ Genetik, Universität Bielefeld, Postfach 100131, D-33501 Bielefeld, Germany; ${ }^{3}$ BRF, Center for Biotechnology (CeBiTec), \\ Universität Bielefeld, D-33594 Bielefeld, Germany
}

Submitted 22 October 2004. Accepted 1 March 2005.

\begin{abstract}
The large majority of plants are capable of undergoing a tight symbiosis with arbuscular mycorrhizal (AM) fungi. During this symbiosis, highly specialized new structures called arbuscules are formed within the host cells, indicating that, during interaction with AM fungi, plants express AMspecific genetic programs. Despite increasing efforts, the number of genes known to be induced in the AM symbiosis is still low. In order to identify novel AM-induced genes which have not been listed before, 5,646 expressed sequence tags (ESTs) were generated from two Medicago truncatula cDNA libraries: a random cDNA library (MtAmp) and a suppression subtractive hybridization (SSH) library (MtGim), the latter being designed to enhance the cloning of mycorrhiza-upregulated genes. In silico expression analysis was applied to identify those tentative consensus sequences (TCs) of The Institute for Genomic Research M. truncatula gene index (MtGI) that are composed exclusively of ESTs deriving from the MtGim or MtAmp library, but not from any other cDNA library of the MtGI. This search revealed 115 MtAmp- or MTGim-specific TCs. For the majority of these TCs with sequence similarities to plant genes, the AMspecific expression was verified by quantitative reverse-transcription polymerase chain reaction. Annotation of the novel genes induced in mycorrhizal roots suggested their involvement in different transport as well as signaling processes and revealed a novel family of AM-specific lectin genes. The expression of reporter gene fusions in transgenic roots revealed an arbuscule-related expression of two members of the lectin gene family, indicating a role for AM-specific lectins during arbuscule formation or functioning.
\end{abstract}

Additional keywords: eNorthern, expression profiling.

More than $80 \%$ of all terrestrial plants, including legumes, are capable of forming a tight symbiosis with fungi of the phylum Glomeromycota (Schüssler et al. 2001). This symbiosis with arbuscular mycorrhizal (AM) fungi is of great economic importance, because an established AM symbiosis leads to better mineral nutrition of the host plants (Harrison 1999). Furthermore, plants harboring an AM symbiosis often show

H. Küster and F. Krajinski contributed equally to this work.

Corresponding author: F. Krajinski; Telephone: +49-511-762 5548; Fax: +49-511-762 4088; E-mail: krajinski@lgm.uni-hannover.de higher levels of resistance against abiotic stress (Augé 2001) and bioprotection against pathogen attacks (Cordier et al. 1996; Newsham et al. 1995; Slezack et al. 2000). In recent years, notable research efforts were carried out in order to advance our insights into the molecular genetics of AM symbiosis. One main aspect in this field of research focused on the analysis of differential gene expression in host plants after colonization by different Glomus spp. microsymbionts (Franken and Requena 2001). In legumes, recent studies on differential gene expression during AM symbiosis centered on the two genetic models Medicago truncatula (Barker et al. 1990) and Lotus japonicus (Handberg and Stougaard 1992), where genome sequences currently are being established (VandenBosch and Stacey 2003). Legumes have the unique capacity to form a second important root endosymbiosis, the legume-Rhizobium spp. symbiosis leading to symbiotic nitrogen fixation; therefore, comparative profiling of gene expression during AM formation and nodulation was initiated (Küster et al. 2004, Manthey et al. 2004 ) in addition to the profiling of gene expression exclusively under AM conditions (Liu et al. 2003). These highthroughput expression profiling experiments significantly advanced our knowledge of genes upregulated during AM formation. Prior to the identification of mycorrhiza-induced genes by transcriptome profiling, only a limited number of genes were identified as being upregulated or specifically expressed in mycorrhizal roots (e.g., encoding a plasma membrane ATPase [Krajinski et al. 2002], a glutathione-S-transferase [Wulf et al. 2003], a chitinase [Salzer et al. 2000], and mycorrhiza-specific phosphate transporters (Harrison et al. 2002; Paszkowski et al. 2002; Rausch et al. 2001]).

In recent years, high-throughput DNA sequencing technologies significantly transformed molecular genetics approaches in legumes and, once whole genome sequences are available, the complete gene inventory of these plants can be studied concerning gene regulation under different symbiotic conditions. A genome sequencing project for $M$. truncatula is underway (VandenBosch and Stacey 2003); however, thus far, the complete genome sequence is not available. Nevertheless, high-throughput expressed sequence tag (EST) sequencing projects identified approximately 190,000 M. truncatula ESTs from more than 40 different cDNA libraries which can serve as a source of information for functional genomics approaches. One of the applications of such EST collections is the identification of genes whose expression differs between the tissue sources from which the libraries were derived (Bortuluzzi and Danieli 1999; Stekel et al. 2000). Using such in silico strate- 
gies, several genes predicted to be up- or downregulated during AM symbiosis were identified in EST populations of two different cDNA libraries originating from AM tissues (Journet et al. 2002). A similar strategy was adopted to identify a notable number of nodule-specific tentative consensus sequences (TCs), which seemed to represent genes solely expressed in root nodules during the symbiosis of legumes with rhizobia (Fedorova et al. 2002). Based on a subset of the M. truncatula and L. japonicus sequences available in EST databases, microarrays were constructed which now enable experimental expression studies of several thousand genes in parallel (Colebatch et al. 2002; El Yahyaoui et al. in press; Küster et al. 2004).

Because a significant number of plant genes show a very tight regulation with respect to the timing and the localization of expression, they tend to be underrepresented in random cDNA libraries and, hence, are difficult to detect on the basis of cDNA-based microarray hybridizations. Thus, it can be assumed that more sophisticated strategies are useful to detect as many differentially expressed genes as possible in a particular tissue. Suppressive subtraction hybridization (SSH) enables the construction of cDNA libraries enriched for sequences upregulated under certain conditions (Diatchenko et al. 1996); therefore, we have, in addition to constructing a random cDNA library, focused our analysis on an SSH-cDNA library from AM roots. That way, we aimed to identify novel, so-far uncharacterized $M$. truncatula genes that are expressed specifically during AM. We report here on the identification of novel genes that previously were not known to be upregulated in $M$. truncatula arbuscular mycorrhiza. Apart from genes connected to different transport as well as signaling processes, a novel family of AM-specific lectin genes was identified. We were able to show that AM-specific lectin sequences did not match previously described $M$. truncatula lectins involved in rootnodule symbiosis, and reporter gene fusions revealed an arbuscule-specific expression of two members of this gene family, indicating a role for AM-specific lectins during arbuscule formation or functioning.

\section{RESULTS}

\section{Generation of EST clusters from}

two M. truncatula-Glomus intraradices AM cDNA libraries.

Two different cDNA libraries were constructed and used for EST sequencing. The first one, designated MtAmp, was generated from $M$. truncatula roots 5 weeks after inoculation with Glomus intraradices. At this time point, all developmental stages of an AM fungus (arbuscules, inter- and intracellular hyphae, appressoria, and vesicles) were present. Mycorrhiza parameters (Trouvelot et al. 1986) were as follows: frequency of infection $(F)=30 \%$, mycorrhization intensity of the whole root system $(M)=16 \%$, mycorrhization intensity within infected root areas $(m)=58 \%$, arbuscule frequency within infected root areas $(a)=63 \%$, and arbuscule frequency of the whole root system $(A)=10 \%$. From this library, a total of 3,805 ESTs was generated, with an average length of $479 \mathrm{bp}$. All ESTs with a length of at least $100 \mathrm{bp}$ were submitted to the EMBL database under accession numbers AJ500944 to AJ504393. The second library, MtGim, was generated by SSH and 1,841 ESTs with an average length of $416 \mathrm{bp}$ were obtained. An initial characterization of 34 cDNAs of the MtGim library revealed the presence of different mycorrhiza-induced genes in this library (Wulf et al. 2003); however, so far, the remaining cDNAs have not been characterized in detail. All MtGim ESTs that were at least $50 \mathrm{bp}$ in length were submitted to the EMBL database and can be accessed under AJ499169 to AJ500943.

Clustering of the MtAmp ESTs revealed 534 TCs and 1,857 singletons, whereas clustering of MtGim ESTs resulted in the identification of $297 \mathrm{TCs}$ and 611 singletons. Of the 534 MtAmp TCs, only $4.9 \%$ were novel compared with all other libraries in The Institute for Genomic Research (TIGR) $M$. truncatula gene index (MtGI). In contrast, a notably higher number of the $297 \mathrm{MtGim}$ TCs encoded novel genes, because $34.7 \%$ of the MtGim TCs did not match any other TIGR MtGI TC. To analyze all TCs derived from both libraries in a single step, all 5,646 MtGim and MtAmp ESTs were clustered to one population of $833 \mathrm{TCs}$ and 2,349 singletons. Our clustering protocol was identical to that used by TIGR (Quackenbush et al. 2000); therefore, in order to ease cross-referencing of our data, we used TIGR MtGI TC numbers as references for our MtAmp and MtGim TCs.

\section{In silico screening for novel AM-specific transcripts.}

In silico expression analysis was applied to identify those TCs that were composed of ESTs exclusively deriving from the MtGim or MtAmp libraries, but not from any other cDNA library of the TIGR MtGI. Therefore, we compared MtGim and MtAmp EST clusters via a BLAST (Altschul et al. 1997) homology search against the TIGR (Liang et al. 2000) sequences. Those of our clusters that hit only sequences of the MtAmp or MtGim library but not of any other library of this database were assumed to represent novel, not previously listed, mycorrhiza-specific genes of M. truncatula. This search revealed 115 MtAmp- or MTGim-specific TCs. These TCs, likely to represent novel mycorrhiza-specific or at least mycorrhiza-related genes, were annotated and grouped into functional categories according to Journet and associates (2002). After BLASTX searches, 10 TCs showed the highest homologies to fungal genes, indicating that these might represent $G$. intraradices genes (Table 1). A large group of $52 \mathrm{TC}$ sequences did not reveal homologies to any other sequence after blastx and also did not contain significant matches to the PROSITE database (Table 2). To obtain first information about the genomic origin of these sequences, the available $M$. truncatula bacterial artificial chromosome (BAC) sequences were searched using blastn. This confirmed an M. truncatula origin for seven of these sequences.

Table 1. MtGim- or MtAmp-specific tentative consensus sequences (TCs) with highest homologies to sequences of fungal origin ${ }^{\mathrm{a}}$

\begin{tabular}{|c|c|c|c|c|c|c|}
\hline MtGI-TC & bp & Annotation & GenBank entry & $E$ value & $N_{\text {MtAmp }}$ & $N_{\text {MtGim }}$ \\
\hline TC64085 & 559 & mRNA for histone $\mathrm{H} 4$ (Agaricus bisporus) & X94189 & $7 e-32$ & $\ldots$ & $4 / 4$ \\
\hline TC68248 & 362 & Isolate RWM_243 28S ribosomal RNA (Glomus mosseae) & AF396793 & e-173 & $\ldots$ & $5 / 5$ \\
\hline TC68246 & 561 & Isolate RWC_658 28S ribosomal RNA ( $G$. caledonium) & AF396794 & e-115 & $\ldots$ & $45 / 45$ \\
\hline TC75488 & 641 & Strain DAOM212595 small subunit ribosomal RNA gene (G. mosseae) & U96143 & $9 e-41$ & $\ldots$ & $2 / 2$ \\
\hline TC67625 & 669 & Cytochrome P-450 cyp509A1 (Cunninghamella elegans) & Q9P493 & $5 e-41$ & $\ldots$ & $2 / 2$ \\
\hline TC59129 & 487 & Glo8 isolate M3 small subunit ribosomal RNA gene (Glomus sp.) & AY 129636 & 0.0 & $\ldots$ & $2 / 2$ \\
\hline TC75848 & 458 & mRNA for hypothetical protein (G. mosseae) & AJ242917 & 0.0 & $\ldots$ & $2 / 2$ \\
\hline TC74547 & 717 & Histone H3 (Mortierella alpina) & Q9HDN1 & $6 e-67$ & $1 / 2$ & $1 / 2$ \\
\hline TC68247 & 390 & Isolate SI_141 28S ribosomal RNA (G. intraradices) & AF396797 & e-177 & $\ldots$ & $11 / 11$ \\
\hline TC75784 & 596 & Vesicular transport protein sec18 homolog (Schizosaccharomyces pombe) & T50122 & $1 \mathrm{e}-12$ & $\ldots$ & $2 / 2$ \\
\hline
\end{tabular}

${ }^{\text {a }} \mathrm{MtGI}=$ Medicago truncatula gene index; $N=$ number of expressed sequence tags in a library. 
The remaining group of 53 TCs displayed significant homologies to plant genes (Table 3). Of these, 20 were homologous to proteins of unknown function of other plants. Thus, these proteins probably encode $M$. truncatula proteins; however, predictions of their putative functions are not possible. Finally, 33 TCs revealed the highest homologies to plant genes with assigned functions. Of those, five encoded putative transporter proteins, four encoded lectin-like proteins, and six gene products involved in signal transduction.

\section{RNA accumulation studies.}

All 33 TCs with significant similarities to plant genes were selected for experimental expression profiling using quantitative real-time reverse-transcription polymerase chain reaction (RT-PCR). For this approach, $M$. truncatula plants were inoculated with $G$. intraradices. Two independent sets of plants were grown and used as biological replicates in RNA accumu- lation analyses. Mycorrhiza parameters of this plant sets were as follows: for set $1, F=100 \%, M=34.73 \%, m=34.73 \%, a=$ $64.42 \%$, and $A=23.42 \%$; and for set $2, F=77.78 \% ; M=$ $40.56 \%, m=52.14 \%, a=61.92 \%$, and $A=25.11 \%$.

The $M t E f-1 \alpha$ gene encoding the constitutively expressed translation elongation factor $1 \alpha$ was chosen for normalization. Specific primer pairs were designed for each gene in a way that selected primer sequences were compared with the TIGR MtGI to extensively verify their specificity. All primers first were used to amplify genomic DNA of M. truncatula. Amplification products were obtained for all genes except TC 60540 and TC 67079 (data not shown), proving that at least the remaining 31 genes originated from $M$. truncatula and not from the microsymbiont. Prior to RNA-accumulation analyses, all RNA preparations were checked for DNA contaminations by PCR using primer combinations that span intron sequences of known gene sequences (data not shown).

Table 2. MtGim- or MtAmp-specific tentative consensus sequences (TCs) without significant homologies after blastx search ${ }^{\mathrm{a}}$

\begin{tabular}{|c|c|c|c|c|c|}
\hline MTGI-TC & bp & $N_{\text {MtAmp }}$ & $N_{\text {MtGim }}$ & Result of blastn search of Medicago truncatula BAC sequences & $E$ value \\
\hline TC63455 & 921 & $1 / 5$ & $4 / 5$ & No hit & $\ldots$ \\
\hline TC71585 & 649 & $1 / 5$ & $4 / 5$ & No hit & $\ldots$ \\
\hline TC71978 & 460 & $\ldots$ & $5 / 5$ & No hit & $\ldots$ \\
\hline TC72388 & 610 & $1 / 4$ & $3 / 4$ & No hit & $\ldots$ \\
\hline TC72546 & 296 & $\ldots$ & $4 / 4$ & No hit & $\ldots$ \\
\hline TC71536 & 575 & $\ldots$ & $5 / 5$ & No hit & $\ldots$ \\
\hline TC72266 & 343 & $\ldots$ & $4 / 4$ & No hit & $\ldots$ \\
\hline TC74813 & 280 & $\ldots$ & $2 / 2$ & Clone mth2-36h10 & 0.15 \\
\hline TC64951 & 675 & $3 / 3$ & $\ldots$ & No hit & $\ldots$ \\
\hline TC73661 & 617 & $1 / 3$ & $2 / 3$ & No hit & $\ldots$ \\
\hline TC73656 & 615 & $\ldots$ & $3 / 3$ & No hit & $\ldots$ \\
\hline TC64827 & 350 & $\ldots$ & $3 / 3$ & No hit & $\ldots$ \\
\hline TC65527 & 202 & $\ldots$ & $3 / 3$ & No hit & $\ldots$ \\
\hline TC73785 & 147 & $\ldots$ & $3 / 3$ & No hit & $\ldots$ \\
\hline TC73242 & 387 & $\ldots$ & $3 / 3$ & No hit & $\ldots$ \\
\hline TC64807 & 632 & $\ldots$ & $3 / 3$ & No hit & $\ldots$ \\
\hline TC64793 & 611 & $1 / 3$ & $2 / 3$ & No hit & $\ldots$ \\
\hline TC74270 & 300 & $\ldots$ & $2 / 2$ & No hit & $\ldots$ \\
\hline TC65745 & 463 & $\ldots$ & $2 / 2$ & No hit & $\ldots$ \\
\hline TC67236 & 385 & $\cdots$ & $2 / 2$ & No hit & $\cdots$ \\
\hline TC74867 & 221 & $\ldots$ & $2 / 2$ & No hit & $\ldots$ \\
\hline TC66251 & 251 & $\cdots$ & $2 / 2$ & No hit & $\ldots$ \\
\hline TC67552 & 434 & $\ldots$ & $2 / 2$ & No hit & $\ldots$ \\
\hline TC67547 & 611 & $\ldots$ & $2 / 2$ & No hit & $\ldots$ \\
\hline TC67067 & 371 & $\ldots$ & $2 / 2$ & No hit & $\ldots$ \\
\hline TC67791 & 408 & $\ldots$ & $2 / 2$ & No hit & $\ldots$ \\
\hline TC65735 & 411 & $\ldots$ & $2 / 2$ & No hit & $\ldots$ \\
\hline TC75233 & 517 & $2 / 2$ & $\ldots$ & Clone mth2-12h1 & 0.79 \\
\hline TC67349 & 377 & $\ldots$ & $2 / 2$ & No hit & $\ldots$ \\
\hline TC75302 & 497 & $\ldots$ & $2 / 2$ & Clone mth2-19c18 & 0.048 \\
\hline TC66690 & 570 & $\ldots$ & $2 / 2$ & Clone mth2-1413 & 0.00 \\
\hline TC65891 & 633 & $\ldots$ & $2 / 2$ & No hit & $\ldots$ \\
\hline TC75970 & 428 & $\ldots$ & $2 / 2$ & No hit & $\ldots$ \\
\hline TC74472 & 655 & $\ldots$ & $2 / 2$ & No hit & $\ldots$ \\
\hline TC74247 & 460 & $\ldots$ & $2 / 2$ & No hit & $\ldots$ \\
\hline TC67260 & 586 & $\ldots$ & $2 / 2$ & No hit & $\ldots$ \\
\hline TC75969 & 802 & $\ldots$ & $2 / 2$ & No hit & $\ldots$ \\
\hline TC74463 & 296 & $\ldots$ & $2 / 2$ & No hit & $\ldots$ \\
\hline TC74186 & 487 & $1 / 2$ & $1 / 2$ & No hit & $\cdots$ \\
\hline TC65823 & 493 & $\ldots$ & $2 / 2$ & Clone mth2-11n13 & 0.19 \\
\hline TC73954 & 304 & $\ldots$ & $2 / 3$ & Clone mth2-27m3 & 0.00 \\
\hline TC67344 & 582 & $\ldots$ & $2 / 2$ & No hit & $\ldots$ \\
\hline TC65995 & 541 & $\ldots$ & $2 / 2$ & No hit & $\ldots$ \\
\hline TC74126 & 418 & $\cdots$ & $2 / 2$ & No hit & $\ldots$ \\
\hline TC75555 & 594 & $\ldots$ & $2 / 2$ & No hit & $\ldots$ \\
\hline TC67674 & 631 & $\ldots$ & $2 / 2$ & Clonemth2-175h23 & 0.00 \\
\hline TC65854 & 374 & $\ldots$ & $2 / 2$ & No hit & $\ldots$ \\
\hline TC70769 & 667 & $\ldots$ & $7 / 7$ & No hit & $\ldots$ \\
\hline TC75097 & 612 & $1 / 2$ & $1 / 2$ & No hit & $\ldots$ \\
\hline TC75784 & 428 & $2 / 2$ & $\ldots$ & No hit & $\ldots$ \\
\hline TC66878 & 601 & $\ldots$ & $2 / 2$ & No hit & $\ldots$ \\
\hline TC75914 & 368 & $\ldots$ & $2 / 2$ & No hit & $\ldots$ \\
\hline
\end{tabular}

${ }^{\mathrm{a}} \mathrm{MtGI}=$ Medicago truncatula gene index; $N=$ number of expressed sequence tags in a library. 
MtEf- $1 \alpha$ was found to be the most abundant gene showing a constant expression in control and mycorrhizal roots. After RTPCR, melting curves were analyzed, and in all reactions, single amplification products were present. Gene induction levels calculated on the basis of real-time RT-PCR are shown in Table 4. Of the 33 TCs analyzed for AM-induced expression, 18 were verified to be at least threefold induced in both samples of mycorrhizal roots. As expected, the AM-specific phosphate transporter gene MtPt4 was more than $10^{4}$-fold induced in both sets of mycorrhizal roots. This corresponds well to the detection of $53 \mathrm{MtPt} 4 \mathrm{ESTs}$ in the MtGim library, in contrast to only 6 MtPT4 ESTs identified in the random cDNA libraries MtBC

Table 3. MtGim- or MtAmp-specific tentative consensus sequences (TCs) with homologies to plant sequences ${ }^{\mathrm{a}}$

\begin{tabular}{|c|c|c|c|c|c|c|}
\hline MtGI-TC & bp & Annotation $^{\text {b }}$ & $\begin{array}{c}\text { GenBank } \\
\text { entry }\end{array}$ & $E$ value & $N_{\text {MtAmp }}$ & $N_{\text {MtGim }}$ \\
\hline \multicolumn{7}{|c|}{ Signal transduction } \\
\hline TC64428 & 494 & NBS-LRR type disease resistance protein (Phaseolus vulgaris) & Q93W58 & $3 e-17$ & $\ldots$ & $3 / 3$ \\
\hline TC66505 & 491 & Lectin-like protein kinase (Arabidopsis thaliana) & Q9FG33 & $9 \mathrm{e}-42$ & $\ldots$ & $2 / 2$ \\
\hline TC74096 & 615 & Receptor like protein $($ A. thaliana $)$ & T49121 & $6 e-56$ & $2 / 2$ & $\ldots$ \\
\hline TC74325 & 1,046 & Seven transmembrane protein MLO2 (Oryza sativa) & Q93XC8 & $\mathrm{e}-123$ & $1 / 2$ & $1 / 2$ \\
\hline TC76060 & 625 & Serine protein kinase-like (A. thaliana ) & T47560 & $6 e-20$ & $\ldots$ & $2 / 2$ \\
\hline TC71483 & 1,236 & Protein kinase (A. thaliana ) & G96593 & $2 \mathrm{e}-74$ & $\ldots$ & $5 / 5$ \\
\hline \multicolumn{7}{|l|}{ Metabolism } \\
\hline TC65799 & 909 & Dihydrodipicolinate synthase (Glycine max) & S50750 & $2 \mathrm{e}-94$ & $1 / 2$ & $1 / 2$ \\
\hline TC67209 & 591 & Phosphoenolpyruvate carboxylase (A. thaliana) & Q9CA39 & $4 \mathrm{e}-76$ & $\ldots$ & $2 / 2$ \\
\hline TC74500 & 206 & $\beta$-Galactosidase (Lactase) (Fragaria ananassa) & Q93X57 & $3 e-19$ & $\ldots$ & $2 / 2$ \\
\hline TC67079 & 555 & Epoxide hydrolase homolog (G. $\max )$ & Q39856 & $2 \mathrm{e}-72$ & $\ldots$ & $2 / 2$ \\
\hline TC76132 & 438 & Blue-copper-binding protein $(O$. sativa $)$ & AAO37971 & $1 \mathrm{e}-21$ & $\ldots$ & $2 / 2$ \\
\hline TC60541 & 960 & Germin-like protein (Medicago truncatula) & AAO32795 & $1 e-72$ & $\ldots$ & $4 / 4$ \\
\hline TC63954 & 473 & Germin-like protein (A. thaliana) & Q9FMA8 & $1 e-32$ & $\ldots$ & $4 / 4$ \\
\hline \multicolumn{7}{|c|}{ Post-transcriptional $^{c}$} \\
\hline TC68426 & 519 & Serin carboxypeptidase-like protein (A. thaliana) & T49188 & $7 e-43$ & $\ldots$ & $2 / 2$ \\
\hline TC66580 & 596 & Cysteine proteinase precursor (Astragalus sinicus) & Q9FS02 & $7 \mathrm{e}-71$ & $\ldots$ & $2 / 2$ \\
\hline TC75569 & 526 & Prolyl endopeptidase (Arabidopsis thaliana) & Q8RXQ7 & $1 e-55$ & $\ldots$ & $2 / 2$ \\
\hline TC71486 & 643 & Phosphoprotein phosphatase (M. sativa) & T09544 & $1 \mathrm{e}-86$ & $\ldots$ & $4 / 5$ \\
\hline TC60540 & 665 & Ribonuclease T2 (Cicer arietinum) & Q9ZQX1 & $2 \mathrm{e}-13$ & $\ldots$ & $2 / 2$ \\
\hline \multicolumn{7}{|c|}{ Cell structure, extracellular ${ }^{\mathrm{d}}$} \\
\hline TC68166 & 1,373 & Agglutinin II precursor $(C$. lutea $)$ & Q39529 & $4 e-54$ & $\ldots$ & $29 / 29$ \\
\hline TC69333 & 1,033 & Bark lectin II precursor (Sophora japonica) & P93536 & $5 e-49$ & $\ldots$ & $6 / 6$ \\
\hline TC75254 & 606 & Agglutinin II precursor $(C$. lutea $)$ & Q39529 & $3 e-23$ & $\ldots$ & $2 / 2$ \\
\hline TC75360 & 599 & Lectin $(S$. japonica $)$ & P93536 & $8 \mathrm{e}-37$ & $\ldots$ & $2 / 2$ \\
\hline \multicolumn{7}{|l|}{ Transport } \\
\hline TC70909 & 672 & MDR-like ABC transporter (O. sativa) & Q8GU68 & $7 e-46$ & $\ldots$ & $7 / 7$ \\
\hline TC63901 & 950 & Copper transporter (A. thaliana) & AAM67571 & $1 \mathrm{e}-17$ & $\ldots$ & $4 / 4$ \\
\hline TC66155 & 242 & Zn transporter ZNT4 (Thlaspi caerulescens) & Q9FPW7 & $4 \mathrm{e}-15$ & $\ldots$ & $2 / 2$ \\
\hline TC73332 & 405 & Ammonium transporter $(O$. sativa $)$ & BAC65232 & $1 \mathrm{e}-12$ & $\ldots$ & $3 / 3$ \\
\hline TC65476 & 552 & Sugar transporter $($ A. thaliana $)$ & AAM78192 & $1 e-65$ & $\ldots$ & $3 / 3$ \\
\hline \multicolumn{7}{|c|}{ Unclassified, function unkn ${ }^{\mathrm{e}}$} \\
\hline TC72502 & 439 & Nodulin-like protein (A. thaliana) & Q9FHJ9 & $1 \mathrm{e}-18$ & $\ldots$ & $4 / 4$ \\
\hline TC67410 & 536 & RING zinc finger protein (A.thaliana) & Q9M8K4 & $3 e-21$ & $2 / 2$ & $\ldots$ \\
\hline TC76092 & 337 & Myotubularin (A. thaliana) & Q9CAF1 & $3 e-20$ & $2 / 2$ & $\ldots$ \\
\hline TC59827 & 722 & Cytokinin-specific binding protein (Vigna radiata) & Q9ZWP8 & $1 e-31$ & $1 / 6$ & $5 / 6$ \\
\hline TC64306 & 963 & Vesicle-associated membrane protein (A. thaliana) & O23429 & e-109 & $1 / 3$ & $2 / 3$ \\
\hline TC67060 & 708 & Mitochondrial inner membrane protein (A. thaliana) & Q9S724 & $1 e-52$ & $2 / 2$ & $\ldots$ \\
\hline \multicolumn{7}{|c|}{ Hypothetical, unkn proteins ${ }^{\mathrm{e}}$} \\
\hline TC71232 & 497 & Hypothetical protein (O. sativa) & AAP03413 & $2 \mathrm{e}-43$ & $\ldots$ & $6 / 6$ \\
\hline TC59539 & 958 & Hypothetical protein $(O$. sativa) & AAO39879 & $6 e-36$ & $\ldots$ & $7 / 7$ \\
\hline TC63326 & 715 & Hypothetical protein OSJNBb0016H12.7 (O. sativa) & AAP03413 & $7 e-66$ & $\ldots$ & $5 / 5$ \\
\hline TC63653 & 614 & Hypothetical protein $(O$. sativa) & Q8H7L0 & $3 e-32$ & $\ldots$ & $4 / 4$ \\
\hline TC73773 & 539 & Hypothetical protein (Plasmodium falciparum) & Q8IEM0 & $4 \mathrm{e}-15$ & $\ldots$ & $3 / 3$ \\
\hline TC64871 & 646 & Hypothetical protein (A. thaliana) & Q8LCS0 & $9 \mathrm{e}-35$ & $3 / 3$ & $\ldots$ \\
\hline TC73566 & 658 & Hypothetical protein F12B17.70 (A. thaliana) & F12B17.70 & $3 e-75$ & $3 / 3$ & $\ldots$ \\
\hline TC64610 & 298 & Hypothetical protein (A. thaliana) & $\mathrm{T} 20 \mathrm{~K} 12.120$ & $6 e-11$ & $\ldots$ & $3 / 3$ \\
\hline TC73173 & 672 & Hypothetical protein [imported] (A. thaliana) & At2g34680 & $8 \mathrm{e}-56$ & $\ldots$ & $3 / 3$ \\
\hline TC64788 & 515 & OSJNBa0014K08.26 protein (O. sativa) & Q8LIY8 & $2 \mathrm{e}-40$ & $\ldots$ & $2 / 2$ \\
\hline TC67169 & 629 & Hypothetical protein $(A$. thaliana $)$ & At1g10490 & $6 e-26$ & $\ldots$ & $2 / 2$ \\
\hline TC66818 & 655 & Hypothetical protein F9N12.8 (A. thaliana) & F9N12.8 & $2 \mathrm{e}-36$ & $\ldots$ & $2 / 2$ \\
\hline TC65882 & 504 & Hypothetical protein $(A$. thaliana $)$ & $\mathrm{T} 16 \mathrm{~L} 1.40$ & $5 e-19$ & $\ldots$ & $2 / 2$ \\
\hline TC63150 & 497 & Hypothetical protein (A. thaliana) & F14L2.70 & $3 e-19$ & $2 / 2$ & $\ldots$ \\
\hline TC66584 & 516 & Hypothetical P0501G01.24 protein (O. sativa) & Q9AX93 & $2 e-59$ & $\ldots$ & $2 / 2$ \\
\hline TC67556 & 725 & $\mathrm{~Gb} \mid \mathrm{AAC} 80617.1$ (A. thaliana $)$ & Q9FFD5 & $7 e-16$ & $2 / 2$ & $\ldots$ \\
\hline TC75304 & 645 & Unknown protein (A. thaliana) & AY088569.1 & $2 \mathrm{e}-90$ & $2 / 2$ & $\ldots$ \\
\hline TC66240 & 450 & Hypothetical protein (A. thaliana) & At2g38010 & $3 e-39$ & $\ldots$ & $2 / 2$ \\
\hline TC66672 & 627 & Hypothetical 71.0-kDa protein & Q8W4D0 & $1 e-53$ & $\ldots$ & $2 / 2$ \\
\hline TC75639 & 723 & Hypothetical protein (A. thaliana) & At $2 \mathrm{~g} 46080$ & $1 \mathrm{e}-71$ & $2 / 2$ & $\ldots$ \\
\hline
\end{tabular}

${ }^{\text {a }}$ MtGI = Medicago truncatula gene index; $N=$ number of expressed sequence tags in a library.

${ }^{\mathrm{b}}$ NBS-LRR = nucleotide binding site-leucine-rich repeat.

${ }^{\mathrm{c}}$ Post-transcriptional modification, protein processing.

${ }^{\mathrm{d}}$ Cell structure and extracellular space.

e Unknown (unkn). 
Table 4. Induction levels of genes represented by MtGim- or MtAmp-specific tentative consensus sequences (TCs) ${ }^{\mathrm{a}}$

\begin{tabular}{|c|c|c|c|c|}
\hline \multirow[b]{2}{*}{ MtGI-TC } & \multicolumn{2}{|c|}{ Induction level $^{\mathrm{b}}$} & \multirow[b]{2}{*}{ Annotation $^{\mathrm{c}}$} & \multirow[b]{2}{*}{ Similarities $^{\mathrm{d}}$} \\
\hline & BR 1 & BR 2 & & \\
\hline \multicolumn{5}{|c|}{ Signal transduction } \\
\hline TC64428 & 10.7 & 59.2 & NBS-LRR type disease resistance protein & $\ldots$ \\
\hline TC66505 & 3.1 & 15.8 & Lectin like protein kinase & $\ldots$ \\
\hline TC74096 & 1.1 & 3.1 & Receptor like protein & $\ldots$ \\
\hline TC74325 & 3.6 & 6.1 & Seven transmembrane protein MLO2 & $61 \%$ identity to MtC50782.1 ${ }^{\mathrm{e}}$ \\
\hline TC76060 & n.d. & 0.4 & Serine protein kinase like & $\ldots$ \\
\hline TC71483 & n.d. & 267.9 & Probable protein kinase & $\ldots$ \\
\hline \multicolumn{5}{|l|}{ Metabolism } \\
\hline TC65799 & 12.4 & 21.0 & Dihydrodipicolinate synthase & $\ldots$ \\
\hline TC67209 & 0.6 & 2.0 & Phosphoenolpyrovatcarboxylase & $\ldots$ \\
\hline TC74500 & 3.9 & 18.8 & $\beta$-Galactosidase & $\ldots$ \\
\hline TC67079 & 5.3 & 18.7 & Epoxide hydrolase homologue & $\ldots$ \\
\hline TC76132 & $24,505.2$ & $69,515.6$ & Blue copper binding protein & $\begin{array}{l}\text { 79\% identity to MtGIM13 } \\
\text { (AW584704) }^{\mathrm{f}}\end{array}$ \\
\hline \multicolumn{5}{|c|}{ Post transcriptional modification, protein processing } \\
\hline TC68426 & 42.5 & 485.0 & Serin carboxypeptidase-like protein & $79 \%$ identity to $\mathrm{MtSCP}^{\mathrm{g}}$ \\
\hline TC66580 & 9.1 & $1,681.3$ & Cystein proteinase precursor & $\ldots$ \\
\hline TC75569 & None & n.d. & Prolyl endopeptidase & $\ldots$ \\
\hline TC71486 & 0.6 & 1.8 & Phospoprotein phosphatase & $\ldots$ \\
\hline \multicolumn{5}{|c|}{ Cell wall and extracellular space } \\
\hline TC75254 & None & None & Agglutinin II precursor & $\begin{array}{l}\text { 64\% identity to MtGIM14 } \\
\text { (TC78055)/MtLEC6 } \\
\text { 46\% identity to MtGIM3 } \\
\text { (TC87043)/MtLEC5 } \\
31 \% \text { identity to MtGIM11 } \\
\text { (TC78315)/MtLEC7 }^{\mathrm{f}}\end{array}$ \\
\hline TC68166 & None & $1,586.2$ & Agglutinin II precursor & $\begin{array}{l}\text { 75\% identity to MtGIM3 } \\
\text { (TC87043)/MtLEC5 }^{\mathrm{f}} \\
51 \% \text { identity to MtGIM14 } \\
\text { (TC78055)/MtLEC6 } \\
\text { 42\% identity to MtGIM11 } \\
\text { (TC78315)/MtLEC7 }\end{array}$ \\
\hline TC75360 & 139.8 & 114.6 & Lectin & $\begin{array}{l}\text { 50\% identity to MtGIM3 } \\
\text { (TC87043)/MtLEC5 }^{\mathrm{f}} \\
\text { 47\% identity to MtGIM14 } \\
\text { (TC78055)/MtLEC6 } \\
47 \% \text { identity to MtGIM11 } \\
\text { (TC78315)/MtLEC7 }^{\mathrm{f}}\end{array}$ \\
\hline TC69333 & 7482.2 & 7477.6 & Bark lectin II precursor & $\begin{array}{l}\text { 75\% identity to MtGIM14 } \\
\text { (TC78055)/MtLEC6 } \\
\text { 43\% identity to MtGIM3 } \\
\text { (TC87043)/MtLEC5 } \\
49 \% \text { identity to MtGIM11 } \\
\text { (TC78315)/MtLEC }^{\mathrm{f}}\end{array}$ \\
\hline TC60541 & 5971.8 & 8699.7 & Germin-like protein & $\begin{array}{l}\text { 68\% identity to MtGIM31 } \\
\text { (TC77375)/MtGLP1 } 1 \text { /h }\end{array}$ \\
\hline TC63954 & 80.6 & 115.2 & Germin-like protein & $\begin{array}{l}\text { 36\% identity to MtGIM31 } \\
\text { (TC77375)/MtGLP1 } 1 \text { /h }\end{array}$ \\
\hline \multicolumn{5}{|l|}{ Transport } \\
\hline TC70909 & n.d. & 46.1 & MDR-like ABC-transporter & $\ldots$ \\
\hline TC63901 & 56.3 & 164.4 & Copper transporter & $\ldots$ \\
\hline TC66155 & 0.4 & n.d. & Zinc transporter & $\ldots$ \\
\hline TC73332 & 130.3 & 450.0 & Ammonium transporter & $\ldots$ \\
\hline TC65476 & 5.4 & 16.3 & Sugar transporter & $\ldots$ \\
\hline \multicolumn{5}{|c|}{ Unclassified, unknown function } \\
\hline TC72502 & 1.1 & 7.0 & Nodulin-like protein & $\ldots$ \\
\hline TC67410 & 0.6 & 2.4 & RING zinc finger protein & $\ldots$ \\
\hline TC76092 & 1.5 & 2.4 & Myotubolarin & $\ldots$ \\
\hline TC59827 & 1.0 & 2.9 & Cytokinin-specific binding protein & $\ldots$ \\
\hline TC64306 & 0.8 & 4.0 & Vesicle-associated membrane protein & $\ldots$ \\
\hline TC67060 & 1.3 & 1.7 & Mitochondrial inner membrane protein & $\ldots$ \\
\hline
\end{tabular}

${ }^{\mathrm{a}} \mathrm{MtGI}=$ Medicago truncatula gene index.

${ }^{\mathrm{b}} \mathrm{BR}=$ biological replicate; n.d. = no products detected using cDNA of nonmycorrhizal or mycorrhizal roots; None = no polymerase chain reaction $(\mathrm{PCR})$ products detectable after amplification of cDNA deriving from non-mycorrhiza roots; PCR products were obtained after amplification of cDNA of mycorrhizal roots

${ }^{\mathrm{c}}$ NBS-LRR = nucleotide binding site-leucine-rich repeat.

${ }^{\mathrm{d}}$ Similarities to previously described arbuscular mycorrhizal-induced genes.

e Manthey et al. 2004.

${ }^{\mathrm{f}}$ Wulf et al. 2001.

${ }^{\mathrm{g}}$ Liu et al. 2003.

${ }^{\mathrm{h}}$ Doll et al. 2001. 
and MHAM (TIGR MtGI), and indicates that the MtGim cDNA collection represents a resource for novel mycorrhizainduced genes that are summarized in Table 4.

\section{A family of $M$. truncatula lectin genes is induced in mycorrhizal roots.}

Notably, four novel lectin-like sequences were strongly induced in mycorrhizal roots (Table 4). Previous reports on $M$. truncatula lectin genes (MtLec 1-4) were focused on genes induced during root nodule development and nitrogen fixation (Bauchrowitz et al. 1996; Mitra and Long 2004). During the initial characterization of the MtGim library (Wulf et al. 2003), three AM-induced lectins represented by TIGR TC 69503 (MtLec5), 69334 (MtLec6), and 69628 (MtLec7) were identified. In the approach presented here, four novel AM-specific lectin-like sequences were found, represented by TIGR TC 68166 (MtLec8), 69333 (MtLec9), 75254 (MtLec10), and 75360 (MtLec 11). Hence, seven different AM-induced lectinsequences have been identified in $M$. truncatula up to now. Amino acid sequences of the AM-induced lectins MtLec5- to 11 were aligned and compared with the previously described nodule-induced lectin sequences. A further nodule-specific lectin-like sequence (TC78397) identified from the TIGR MtGI by in silico expression profiling also was included in this analysis. The multiple alignment revealed that AM-induced lectin sequences group in one branch when compared with the lectin sequences induced during the root nodule symbiosis (Fig. 1), indicating a putative subfamily of AM-specific members within the group of $M$. truncatula lectin-like sequences.

To obtain information on the localization of AM-specific lectins, the promoter sequences of two genes (MtLec5 and MtLec 7) were used in reporter gene studies. The genomic sequence of MtLec5 was amplified from BAC clone mth2-20e4 (GenBank accession no. AC126010), whereas the MtLec7 promoter sequence was cloned by inverse PCR. For reporter gene studies, 1,059 bp of the MtLec5 promoter (position -1060 to -1 relative to the ATG) and 1,503 bp (position -1504 to -1 relative to the ATG) of the MtLec 7 promoter were fused to the gus reporter gene. With both constructs, a comparable pattern of promoter activity was observed. No reporter gene activities were found in roots of nonmycorrhizal plants (data not shown); however, strong reporter gene activities occurred in transgenic roots colonized by $G$. intraradices (Fig. 2). Both promoters showed high activity in arbuscule-containing cells, but no activity in the vicinity of appressoria, intercellular or intracellular fungal hyphae, and vesicles Thus, MtLec5 and $M t L e c 7$ seem to be specifically activated in arbuscule-containing cells.

A comparison of the MtLEC5 and MtLEC7 amino acid sequences showed that both sequences share $37.8 \%$ identity (Fig. 3 ). For these two lectins, a cleavable $\mathrm{N}$-terminal signal sequence and a putative apoplastic localization was predicted with a certainty of 0.8 using the PSORT software (Nakai and Kanehisa 1992), suggesting an extracellular localization of these proteins.

\section{DISCUSSION}

Data presented in this report contribute to the theory that plants, which are susceptible to AM fungi, possess a set of genes specifically induced after colonization with AM fungi. A notable number of ESTs were generated from two cDNA libraries (MtAmp and MtGim) of M. truncatula roots colonized by the AM fungus $G$. intraradices. The resulting population of tentative consensus sequences was used in an in silico screen for novel AM-specific sequences by searching for TCs within the MtGI exclusively composed of ESTs derived from the MtAmp or MtGim library. In silico strategies also have been used by Journet and associates (2002) to identify genes regulated during root nodule and AM endosymbiosis using likelihood ratio ( $R$-value) statistics by comparing EST counts in

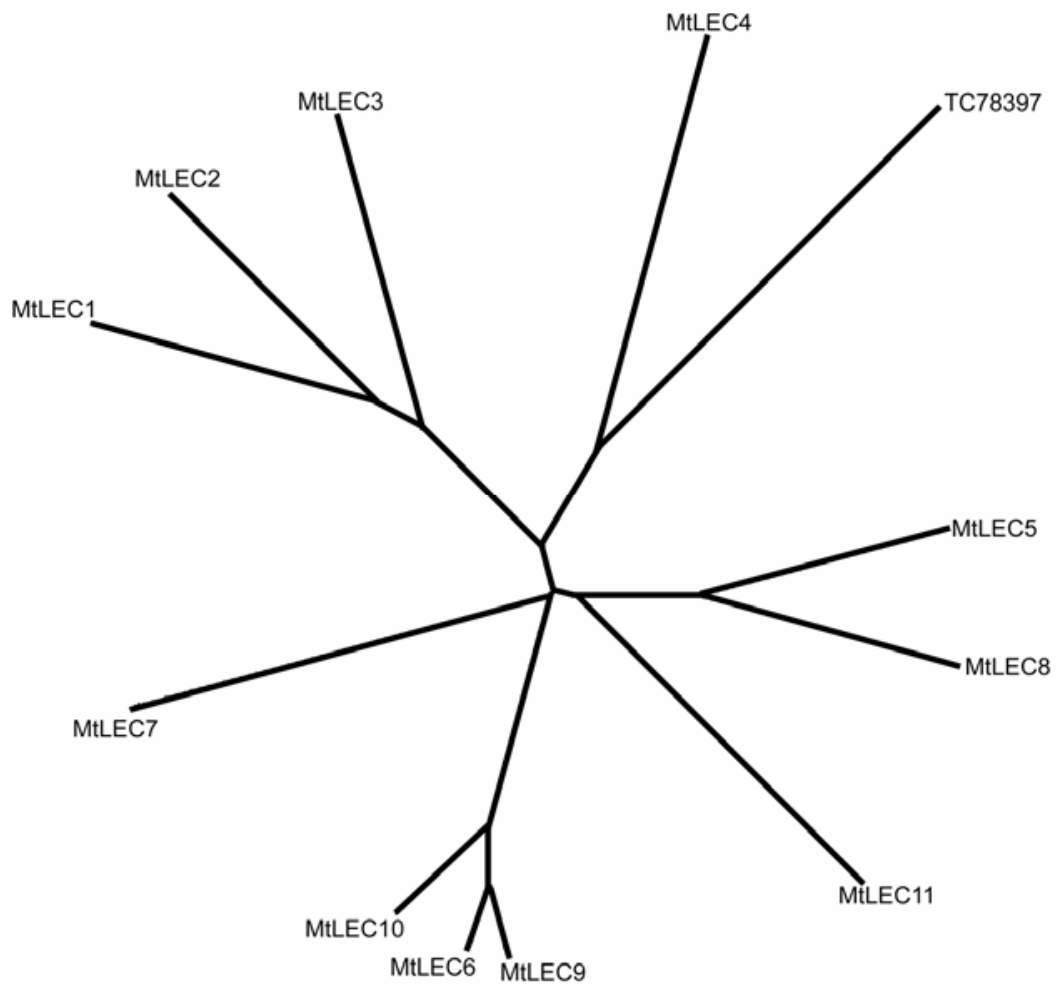

Fig. 1. Unrooted tree based on ClustalW alignment. The following sequences were included: MtLec1 (X60386), MtLec2 (X60387), MtLec3 (X82216), MtLec4 (TC77066), MtLec5 (TC69503), MtLec6 (TC69334), MtLec7 (TC6928), MtLec8 (TC68166), MtLec9 (TC69333), MtLec10 (TC75254), MtLec11 (TC75360), and the nodule-specific lectin-like sequence encoded by TC78397. 
cDNA populations of different tissues. This is in contrast to the here-applied strategy of screening for a novel set of AMspecific genes which are exclusively composed of MtGim or MtAmp ESTs.

This stringent search strategy revealed 115 novel AM-specific TCs. Annotation of these sequences indicated that 10 of them showed the highest similarities to fungal sequences and most likely are derived from the microsymbiont $G$. intraradices. Most of these putative fungal genes encoded ribosomal RNAs but one sequence was highly homologous to a previously characterized non-rRNA gene of an AM fungus, $G$. mosseae (Franken et al. 2000).
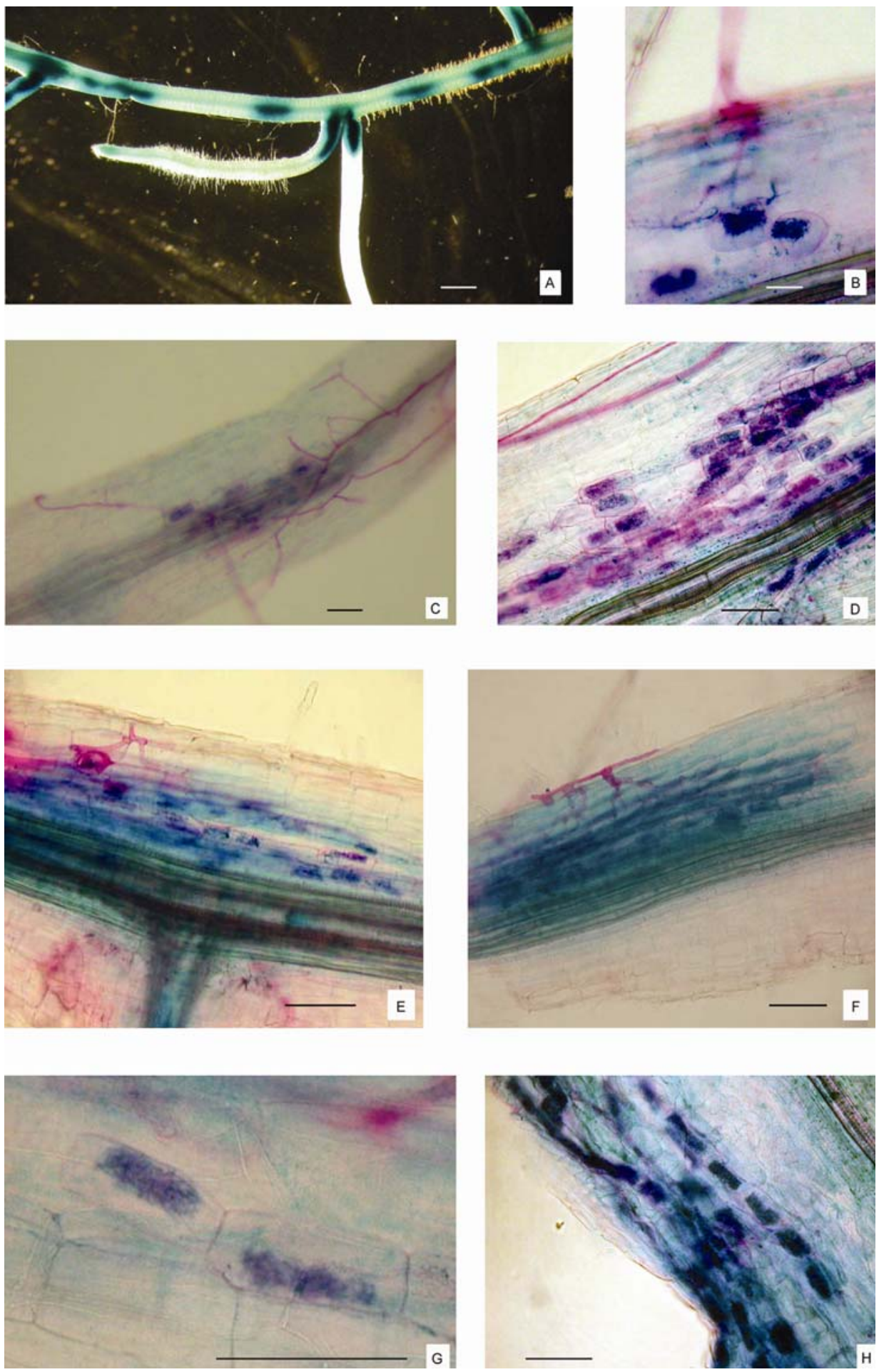

Fig. 2. Promoter activities in Glomus intraradices-colonized hairy roots. Histochemical analysis of transgenic Medicago truncatula roots carrying A, B, C, and $\mathbf{D}$, the MtLec5 GUS or E, F, G, and $\mathbf{H}$, MtLec7-GUS fusions. M. truncatula plants with Agrobacterium rhizogenes-transformed hairy roots were colonized by G. intraradices and stained for GUS activity 3 weeks after colonization. B through $\mathbf{H}$, Double stainings for GUS activity and subsequent acid fuchsin staining to detect G. intraradices. A, Intense MtLec5 promoter activity is detectable in root parts colonized by the arbuscular mycorrhizal fungus (magnification bar: $2 \mathrm{~mm}$ ). B and $\mathbf{D}$, Arbuscules showing intense MtLec5 promoter activity (magnification bars: 10 and $25 \mu \mathrm{m}$, respectively). C, MtLec5 activity is localized in inner cortical cell layers where arbuscules have been formed; no GUS activity can be detected at the root surface after contact with $G$. intraradices hyphae (magnification bar: $20 \mu \mathrm{m}$ ). No MtLec 7 promoter activity was observed in the vicinity of $\mathbf{E}$, vesicles (magnification bar: $25 \mu \mathrm{m})$ or $\mathbf{F}$, appressoria (magnification bar: $50 \mu \mathrm{m}$ ); $\mathbf{G}$ and $\mathbf{H}$, arbuscules showing intense MtLec7 promoter activity (magnification bars: $25 \mu \mathrm{m}$ ). 
One of the most surprising outcomes of this study was the identification of 52 TCs without homologies on an amino acid level to previously identified sequences. In addition to comprehensive EST collections, several plant genome sequences that either sequenced completely or sequenced to a large extent are available to date; therefore, it might be anticipated that $M$. truncatula ESTs at least weakly match sequences from other plant EST or genome sequence data. A blastn search within the presently available $M$. truncatula BAC sequence collection, confirmed a plant origin for seven of these sequences. For these seven genes, no putative homologues have been identified so far in other plant genomes; therefore, they are extremely interesting for further studies in AM research and could reveal novel mechanisms. A notable number of the $52 \mathrm{TCs}$ without significant homologies also probably correspond to hitherto unknown fungal genes. To gain information on the genetic program of $M$. truncatula activated in mycorrhizal roots, only plant-derived genes which could be assigned to putative functions have been further studied concerning their RNA accumulation pattern in mycorrhizal and control roots, and an induced expression in mycorrhizal roots was confirmed for the majority of the analyzed genes.

The exchange of nutrients is supposed to be the key element of an AM fungus. In the past, numerous efforts have been made to identify plant genes involved in these transport processes (Harrison 1996; Hildebrandt et al. 2002; Liu et al. 1998). Very recently, mycorrhiza specifically expressed phosphate transporters have been identified in several plant species (Harrison et al. 2002; Paszkowski et al. 2002; Rausch et al. 2001). In this study, sequence annotation raised evidence for an involvement of copper and ammonium transporters during symbiotic nutrient transfer. Studies using ${ }^{15} \mathrm{~N}$ showed that AM fungi are able to take up ammonium as well as nitrate from the soil environment (George et al. 1992; Johansen et al. 1992) and the proteins presented here could be responsible for the allocation of copper or $\mathrm{N}$-compounds in mycorrhizal roots. For copper transporters, an involvement during the root nodule symbiosis could be demonstrated already: a nodule-specific copper transporter was identified by an in-silico approach (Fedorova et al. 2002), indicating that $M$. truncatula possesses both a mycorrhiza- and nodule-specific copper-transporter gene, which probably are localized in specific tissues.

Within the group of genes involved in signalling processes, a gene with similarities to nucleotide binding site (NBS) leucine-rich repeat (LRR) resistance-like protein was found to be more than 10-fold induced in mycorrhizal roots. NBS-LRR resistance genes represent the largest class of disease resistance genes (Hammond-Kosack and Jones 1996) and have been shown to be represented by at least 58 members within the NBS-LRR resistance gene family in $M$. truncatula (Zhu et al. 2002). NBS-LRR resistance-like genes encode receptors with high specificities and can be involved in different signal transuction pathways (Ellis et al. 2000). Thus, the AM-induced NBS-LRR resistance-like gene identified here could represent a receptor involved in AM-specific signaling processes which is transcriptionally activated during AM symbiosis. A second upregulated gene which also is involved in signaling processes shows similarities to members of the plant-specific seventransmembrane MLO family. Members of this protein family are suggested to have a function similar to that of $G$ proteincoupled receptors of animal and fungi (Devoto et al. 2003).

Annotation of several AM-induced sequences showed that they belong to sequence families for which AM-induced members already have been described. The phenomenon that several members of the same gene family show increased RNA accumulation in mycorrhiza compared with control roots was observed for the family of germin-like sequences (Doll et al. 2003; Wulf et al. 2003), serine-carboxypeptidases (Liu et al. 2003), blue-copper binding proteins, and lectins (Wulf et al. 2003).

In this study, two germin-like proteins (GLPs) have been demonstrated to be upregulated in mycorrhizal roots. A further GLP gene of $M$. truncatula, MtGLP1, recently was described to be upregulated specifically in AM fungi (Doll et al. 2003; Wulf et al. 2003). Together with the two GLP-like TCs presented here, three different AM-induced GLPs seem to be involved in AM symbiosis. A serine carboxypeptidase-like sequence was found to be more than 40-fold induced in AM roots compared with control roots; however, this gene is not identical to the AM-induced serine carboxypeptidase which was identified by array hybridizations (Liu et al. 2003). The gene represented by TC 76132, which more than $10^{4}$-fold upregulated in mycorrhizal roots compared with control roots, also belongs to a family of AM-specific sequences. These sequences show similarities to blue-copper binding proteins, or plantacyanins. Although nothing is known about functions of these copper-binding domain-containing proteins, some bluecopper binding proteins have been identified as nodulins (Fedorova et al. 2002; Greene et al. 1998; Jiménez-Zurdo et al. 2000) and a blue-copper binding protein-like sequence has been described to be AM-specifically expressed (Wulf et al. 2003) or induced in AM roots (Journet et al. 2002). Hence, it might be anticipated that members of this gene family play specific roles during both root nodule and AM endosymbiosis.

The most important result of this study is probably the identification of a group of seven AM-specific lectin-like sequences in $M$. truncatula. In a previous report, three different $M$. truncatula lectin-like sequences were described to show an increased expression in mycorrhizal roots (Wulf et al. 2003). Four different new, lectin-like sequences have been identified

$\begin{array}{ll}\text { Mt LEC5 } & \text { MANSIPKLLATQNPFSVSLSIFFFLLLLINNVKSDSLSFNFPKFDTDA } \\ \text { MtLEC7 } & \text { MAINTSR---TQILF---ITIISFLILAQN-VNS--AAFTVSNFDPYK } \\ \text { MtLEC5 } & \text { GGVLQLTKKDQFGNPSPHSVGFSAFFGAIQLSDKQSGKVADFTTEFS } \\ \text { MtLEC7 } & \text { DGSIHLT-----NVIPNSAGRASWGGPVRLWDADTGNLAGFTSVFS } \\ \text { MtLEC5 } & \text { GFAFYIASLDYDFPEKSSDGGFLGLFDKETAFNTSKNSIVAVEFDSFA } \\ \text { MtLEC7 } & \text { GITFFIAPFNSHIPKNSS-GGFLGLFNAETALNTYQNRIVAVEFDSF } \\ \text { MtLEC5 } & \text { PHIGIDINTIESSISVPWPIDRQPQGTIGKARISYNTASKDLSVFVT } \\ \text { MtLEC7 } & \text { PHVGIDVNSIASVTTAPWKTGSILTGFNAIAFVNYEPVEKNLSVVVRY } \\ \text { MtLEC5 } & \text { VSYPIDFASVLSEWVYVGFSGATGQVAETHDILSWSFVSNL- } 274 \\ \text { MtLEC7 } & \text { VSFIIDLRTVLPEWVRIGFSGATGQLVELHKILSWTFKSSFQ } 266\end{array}$

Fig. 3. MtLEC5 and MtLEC7 amino acid sequence alignment. Identical amino acids are marked by gray background. The predicted N-terminal signal sequences are indicated by bold letters.

$\mathbf{7 7 8}$ / Molecular Plant-Microbe Interactions 
in this study; all of them were proven to be strongly induced in AM. Thus, seven different AM-specific lectin-like sequences of $M$. truncatula have been identified so far. Lectins are proteins that reversibly bind to specific mono- or oligosaccharides (Peumans and van Damme 1995). Genes encoding lectins have been found in plants, animals, microbes, and viruses. The sequences differ remarkably with respect to their molecular structure and are divided in different subfamilies. For some members of the legume lectins, a function as determinants of specificity in the root nodule symbiosis could be demonstrated by gain-of-function analyses (Diaz et al. 1989; Hirsch et al. 1995; van Rhijn et al. 1998). Nevertheless, sequences of this subfamily also must have other functions, because sequences with high similarity to legume lectins also have been identified in nonleguminous plants and animals (Wang et al. 2003). The identification of numerous different lectin-like sequences presented here which all show increased RNA accumulation in mycorrhizal roots indicates an important role for these proteins during AM symbiosis. Reporter gene studies showed an arbuscule-specific transcription for two members of the AMspecific lectin family, suggesting a role during arbuscule formation and functioning during late stages of the AM symbiosis. No promoter activities were detected in the vicinity of appressoria which represent early steps of AM development. Appressoria are formed only at epidermal cells of host plants (Giovanetti et al. 1993; Nagahashi and Douds 1997), indicating a host plant-fungus recognition at this step. Thus, the two lectins MtLec5 and MtLec7 do not play a role during recognition at early steps of symbiosis development. One possible function of AM-specific lectins could be a direct interaction with the fungal microsymbiont during arbuscule formation by binding of fungal surface carbohydrates. Because AM fungi possess a thick and rigid cell wall, it is unlikely that plant lectins can directly bind to glucoconjugates on the fungal membranes and, thus, directly influence intracellular processes in the fungus; however, plant lectins could bind to carbohydrates exposed to fungal cell wall surfaces and, therefore, indirectly regulate molecular processes during symbiosis. Biochemical studies targeted at identifying the carbohydrates which are recognized by the AM-specific lectins remain to be done to strengthen this hypothesis. Another possible function of lectins during AM symbiosis is a role as storage for organic nitrogen. Immunolocalizations have shown that lectins accumulate in vacuoles, parenchyma cells, and the extracellular matrix of peanut nodules, indicating a role as storage proteins (VandenBosch et al. 1994). An extracellular localization was predicted for the two AM-specific lectins MtLec5 and MtLec7 pointing to a similar function of AM-specific lectins. Recent studies by Bauchrowitz and associates (1996) showed that three M. truncatula lectin genes (MtLecl to -3) are expressed throughout nodule development. Except for $M t L e c 2$, which is presumably a pseudogene (Bauchrowitz et al 1992), these lectins also were transcribed in nonsymbiotic tissues. In contrast, in silico expression profiling using the MtGI revealed the identification of one nodule-specific gene, MtLec4, which shows an expression correlated to bacterial penetration of the cortex cells and sustained cell divisions (Mitra and Long 2004). Amino acid comparison of AM-specific, nodule-specific, and nodule-correlated lectins revealed that seven AM-specific sequences form a unique branch in the corresponding tree, suggesting that AM-specific and noduleenhanced lectins might have different functions during root endosymbioses.

The strategy of coupling EST sequencing with in silico and experimental expression analysis has proven to be a powerful tool for identifying novel $M$. truncatula genes specifically regulated in endomycorrhizae. Our results suggest an involve- ment of several lectins in the AM symbiosis and, although their individual role remains to be elucidated, a specific role during arbuscule development or functioning can be proposed.

\section{MATERIALS AND METHODS}

\section{Plant growth and inoculations.}

For RT-PCR, plants were grown as described by Wulf and associates (2003). Briefly, seed of M. truncatula cv. Jemalong A17 were sterilized by a 10 -min treatment with concentrated sulfuric acid, washings with distilled water, and a 5-min incubation in $6 \% \mathrm{NaClO}$. Germination of the seed occurred at room temperature in the dark for 2 days. For AM inoculation, seedlings were planted into a 1:2 mixture of expanded clay and vermiculite. Inoculations with $G$. intraradices were carried out with a commercially available inoculum (Biorize Sarl, Dijon, France). After 3 weeks, all plants were harvested. Mycorrhization was quantified as described by Trouvelot and associates (1986).

\section{cDNA libraries and sequencing.}

The MtGim SSH library was generated as described earlier (Wulf et al. 2003). The MtAmp library was generated by MediGenomix (Martinsried, Germany) from mycorrhizal roots of $M$. truncatula using a directional cloning strategy with a cutoff of $500 \mathrm{bp}$. cDNA was prepared by reverse transcription of poly A+ enriched RNA. The cDNA was directionally ligated into the pGEM-T vector (Promega, Madison, WI, U.S.A.) using GCATGCGGCCGAGGCGGCCGACATG and CTGCAGGCCATTATGGCCGGG adaptors. Plasmids containing cDNA inserts were propagated in Escherichia coli DH10B cells. cDNA sequences were obtained using standard protocols on the MegaBace 1000 sequencer (Amersham Biosciences, Freiburg, Germany).

\section{Sequence processing, annotation, and clustering.}

To cluster and annotate the ESTs obtained, the BioMake software package was used. BioMake processes sequence data as follows: beginning with the raw EST trace files, a normalization step using phred (Ewing et al. 1998) was performed. Afterward, low-quality regions were removed according to the phred 13 quality definition (Ewing and Greene 1998). Finally, the vector content needed to be clipped, leading to EST reads in fasta file format. Clustering of the EST reads also was performed by the BioMake software package according to the TIGR clustering algorithm (Liang et al. 2000). The sequence data obtained consist of TCs and single (unclustered) EST reads, called singletons. Comparisons to the TIGR MtGI were done in order to identify identical TCs. BLAST comparisons against the GenBank nonredundant database and annotations also were done using the BioMake software. BLASTX searches were carried out in order to identify homologous genes in other organisms (Altschul et al. 1997).

\section{In silico analysis of gene expression.}

To identify TCs representing putative mycorrhiza-specific genes, an electronic Northern (eNorthern) algorithm was developed. We compared MtGim and MtAmp EST clusters via a BLAST (Altschul et al. 1997) homology search against TIGR (Liang et al. 2000) using an e-value cut-off of $1 \mathrm{e}^{-10}$ and sequence identity of at least $95 \%$. Those of our clusters that hit only the MtAmp or MtGim library were assumed to represent novel mycorrhiza-specific genes of M. truncatula.

\section{Quantitative real-time RT-PCR.}

Primer design and quantitative RT-PCR was carried out according to Wulf and associates (2003). All quantitative real- 
time RT-PCR experiments were repeated (technical control) in order to verify RNA-accumulation values. Primer sequences used for RT-PCR are shown in Table 5.

\section{Isolation of lectin promoters \\ from BAC sequences and by inverse PCR.}

For amplification of the MtLec 5 promoter, $1 \mathrm{ng}$ of genomic DNA was amplified with specific primers (5' to $3^{\prime}$ : GAA TTC GGG AAA ATT GAC TAA CGT TGT GAA A and GGA TTC GGT ATT ATG TTG TGT ATG ATG C) deduced from the corresponding BAC sequence. The PCR product was cut with EcoRI and BamHI and cloned into the corresponding sites into the pLP 100 vector. For the inverse PCR to amplify the MtLec 7 promoter region, $2 \mu \mathrm{g}$ of genomic M. truncatula DNA was cut with the restriction enzymes EcoRI, XbaI, XhoI, PvuI, PaeI, or HindIII. Circularization of $50 \mathrm{ng}$ of digested DNA was carried out in $30 \mu \mathrm{l}$ using $0.6 \mathrm{U}$ of T4-DNA ligase at $16^{\circ} \mathrm{C}$. The flanking regions were amplified using $10 \mathrm{ng}$ of recircularized DNA and MtLec7-specific outward orientated primers (5' to $3^{\prime}$ : gagatggaattaccttcttca and gatggtaatgaaaaggatttgagtcc). Of the resulting PCR fragment, a 1,503-bp MtLec7 promoter region was amplified using specific primers (5' to $3^{\prime}$ : GGG GAC AAG TTT GTA CAA AAA AGC AGG CTC ACC GCG CAT AAT GAT TGA GG and GGG ACC ACT TTG TAC AAG AAA G CT GGG TGA ATC CGC GAT GGT TCT AAA TTA GTG) and $1 \mathrm{ng}$ of genomic DNA as template. The resulting PCR product was cloned into the pMDC163 vector (Curtis and Grossniklaus 2003).

\section{Agrobacterium rhizogenes-mediated transformation of M. truncatula.}

Using sequence-specific primers with restriction enzyme recognition sites, 1,059 bp of the MtLec5 promoter region were cloned in front of the GUS gene in the binary vector pLP100 (Szabados et al. 1995). A 1,503-bp MtLec6 promoter fragment was cloned in front of the GUS gene of the pMDC163 binary vector (Curtis and Grossniklaus 2003) using the Gateway cloning system (Invitrogen, Karlsruhe Germany). Agrobacterium rhizogenes strain ARqua 1 (Quandt et al. 1993) was transformed with the binary plasmids via electroporation. $M$. truncatula roots were transformed according to a modified protocol of Vieweg and associates (2004).

\section{Histochemical analysis of transgenic roots.}

Histochemical assays for GUS activity were performed as described by Jefferson and associates (1997). Roots were incubated in the staining solutions in the dark at $37^{\circ} \mathrm{C}$ for 1 to $2 \mathrm{~h}$ and subsequently cleared in $70 \%$ ethanol for $1 \mathrm{~h}$.

\section{Online resources.}

Sequences have been analyzed concerning conserved short protein patterns using the PROSITE (Gattiker et al. 2002; Sigrist et al. 2002) database at ExPASy. Searches for sequences similarities were done using Blast2X (Altschul et al. 1997). M. truncatula genomic sequence data were obtained from the $M$. truncatula Genome Sequencing Project at the Advanced Center for Genome Technology of the University of Oklahoma, (Norman, OK, U.S.A.) and the Noble Foundation (Ardmore, OK, U.S.A.). The N-terminal sequences were identified using the PSORT protein sorting predication tool (Nakai and Kanehisa 1992).

\section{Multiple amino acid sequence alignments.}

Open reading frames of TIGR TCs were translated into amino acid sequences and aligned using ClustalW (Jeanmougin et al. 1998) at the EMBnet ClustalW server. Of the aligned

Table 5. Primer sequences used for quantitative real-time reverse-transcription polymerase chain reaction

\begin{tabular}{|c|c|c|}
\hline MtGI-TC ${ }^{a}$ & Left primer $\left(5^{\prime}-3^{\prime}\right)$ & Right primer $\left(5^{\prime}-3^{\prime}\right)$ \\
\hline TC64428 & tacgaaaatcaaacatttcac & gcagagatgatgacaataaga \\
\hline TC66505 & atctctttattgtttccaagg & aggatagaggatcaaattcaa \\
\hline TC74096 & aattcaacctttatcaccatt & attatcttgetcgatcttctc \\
\hline TC74325 & aataagatggatagtggcatt & aattgtaaacgttcataagca \\
\hline TC76060 & ttcacaagttctctcattcag & agaacactttcaattttaggg \\
\hline TC71483 & tcctatcttcccaagtaagag & aattgctgttaagcaacataa \\
\hline TC65799 & tgggataacctctaaagaaag & ttttgttggtatcaaagagtg \\
\hline ТC67209 & accagaatcagaatatccaac & ttgcagtagagcttttacaga \\
\hline TC74500 & gtagtcacttctatcagccgt & catctatgatttcaagtttcg \\
\hline ТC67079 & aacttcctttagcaatttcag & gtttcttgtagctcatgattg \\
\hline TC68426 & aaaaatggttcaactggttat & tgtcgatgagatacttgatgt \\
\hline TC66580 & atgaattcttaaccaaccaat & tttccgtaactattgatgcta \\
\hline ТC75569 & gaaccagaaagacataaggag & aatgcttattgcatcaaagta \\
\hline TC71486 & gctttaatatttggaaagagc & gtatacgtttggtgctgataa \\
\hline TC60540 & agaagtgtccacacacaagta & caacactttatggaaaatgaa \\
\hline TC68166 & agtgaaagaccatgaaagaat & ataagttataatcctgectcg \\
\hline TC69333 & caatgtgaggatattgagatg & tcttttatcgtgaacacaaac \\
\hline TC75254 & gatactgacatggcaacttta & aactggttgaaacacatgata \\
\hline TC75360 & ctatcaaattcaacaaggaca & aactcaaacggtagacaagat \\
\hline TC73332 & accatttgaagttcacctaat & ctacaacgtttaatgacgag \\
\hline TC65476 & gaacacaacagtcaaaacaac & atagtccagccattattcagt \\
\hline TC63901 & aaataaaaattttggtggtgt & gacataccaataagcacttga \\
\hline TC66155 & tgatagcagctgattttctta & atctaccaaaattgaattgga \\
\hline TC70909 & caaaattgtagtgttggagaa & ataaatgcatattgtgttgga \\
\hline TC72502 & attctattgcatcattcatca & ggatcttgtcttgtctaaacc \\
\hline TC76132 & tcttctcccataggttgtaat & ttttgtagttggagatgaaaa \\
\hline TC67410 & tccetcctcatcaatactact & cagagtgtgtttatgcaagtt \\
\hline TC76092 & gattaacgacaaaaaggatct & gcttgaaataactgtcatcaa \\
\hline TC59827 & atgtcttggtaggtttgactt & gtaaattatcaaagggaggtg \\
\hline TC60541 & ttgctagcacattgtttaact & agttacatcaaccatttcaca \\
\hline TC63954 & agctctttcacttttagctgt & gcaaagactggagttactctt \\
\hline TC64306 & cataaccatcttcaacaagaa & actcagttacagagcacaatg \\
\hline ТC67060 & tactttcactgtctctgatcg & ctggttatgacgattaacaaa \\
\hline
\end{tabular}

${ }^{\mathrm{a}} \mathrm{MtGI}=$ Medicago truncatula gene index $; \mathrm{TC}=$ tentative consensus sequence . 
amino acid sequences, $3^{\prime}$ and $5^{\prime}$ extremities as well as gap columns were removed and the remaining sequence block was used to calculate a tree by the neighbor-joining method.

\section{ACKNOWLEDGMENTS}

This work was supported by the Deutsche Forschungsgemeinschaft SPP 1084 "Molecular Basics of Mycorrhizal Symbioses." H. Küster acknowledges financial support from the International NRW Graduate School in Bioinformatics and Genome Research. The authors thank B. Linke and D. Bartels (CeBiTec, Bielefeld University) for bioinformatics assistance in primer design, protein motif scans, and in silico profiling. P. Franken (IGZ Grossbeeren) and U. Grunwald are acknowledged for providing plant material and D. Barker (INRA-CNRS Toulouse, France) is acknowledged for providing the binary vector $\mathrm{pLP} 100$.

\section{LITERATURE CITED}

Altschul, S. F., Madden, T. L., Schaffer, A. A., Zhang, J., Zhang, Z., Miller, W., and Lipman, D. J. 1997. Gapped BLAST and PSI-BLAST: a new generation of protein database search programs. Nucleic Acids Res. 25:3389-3402.

Augé, R. M. 2001. Water relations, drought and VA mycorrhizal symbiosis. Mycorrhiza 11:3-42.

Barker, D. G., Bianchi, S., and Blondon, F. 1990. Medicago truncatula, a model plant for studying the molecular genetics of the Rhizobium-legume symbiosis. Plant Mol. Biol. 8:40-49.

Bauchrowitz, M. A., Barker, D. G., and Truchet, G. 1996. Lectin genes are expressed throughout root nodule development and during nitrogenfixation in the Rhizobium-Medicago symbiosis. Plant J. 9(1):31-43.

Bauchrowitz, M. A., Berker, D. G., Nadaud, I., Rougé, P., and Lescure, B. 1992. Lectin genes from the legume Medicago truncatula. Plant Mol. Biol. 19:1011-1017.

Bortoluzzi, S., and Danieli, G. A. 1999. Towards an in silico analysis of transcription patterns. Trends Genet. 15:118-119.

Colebatch, G., Kloska, S., Trevaskis, B., Freund, S., Altmann, T., Udvardi, M. 2002. Novel aspects of symbiotic nitrogen fixation uncovered by transcript profiling with cDNA arrays. Mol. Plant-Microbe Interact. $15: 411-420$.

Cordier, C., Gianinazzi, S., and Gianinazzi-Pearson, V. 1996. Colonisation patterns of root tissues by Phytophthora nicotianae var. parasitica related to reduced disease in mycorrhizal tomato. Plant Soil 185:223-232.

Curtis, M. D., and Grossniklaus, U. 2003. A Gateway cloning vector set for high-throughput functional analysis of genes in planta. Plant Physiol. 133:462-469.

Devoto, A., Hartmann, H. A., Piffanelli, P., Elliott, C., Simmons, C., Taramino, G., Goh, C.-S., Cohen, F. E., Emerson, B. C., Schulze-Lefert, P., and Panstruga, R. 2003. Molecular phylogeny and evolution of the plant-specific seven-transmembrane MLO family. J. Mol. Evol. 56:7788.

Diatchenko, L., Lau, Y. F., Campbell, A. P., Chenchik, A., Moqadam, F., Huang, B., Lukyanov, S., Lukyanov, K., Gurskaya, N., Sverdlov, E. D., and Siebert, P. D. 1996. Suppression subtractive hybridization: a method for generating differentially regulated or tissue-specific cDNA probes and libraries. Proc. Natl. Acad. Sci. U.S.A. 93:6025-6030.

Diaz, C. L., Melchers, L. S., Hooykaas, P. J. J., Lugtenberg, B. J. J., and Kijne, J. W. 1989. Root lectin as a determinant of host specificity in the Rhizobium-legume symbiosis. Nature 338:579-581.

Doll, J., Hause, B., Demchenko, K., Pawlowski, K., and Krajinski, F. 2003. A member of the germin-like protein family is a highly conserved mycorrhiza-specific induced gene. Plant Cell Physiol. 44:1208-1214.

Ellis, J., Dodds, P., and Pryor, T. 2000. Structure, function and evolution of plant disease resistance genes. Curr. Opin. Plant Biol. 3:278-284.

El Yahyaoui, F., Küster, H., Ben Amor, B., Hohnjec, N., Pühler, A., Becker, A., Gouzy, J., Vernié, T., Gough, C., Niebel, A., Godiard, L., and Gamas, P. Expression profiling in Medicago truncatula identifies more than 750 genes differentially expressed during nodulation, including many potential regulators of the symbiotic program. Plant Physiol. In press.

Ewing, B., and Green, P. 1998. Base-calling of automated sequencer traces using Phred. II. Error probabilities. Genome Res. 8:186-194.

Ewing, B., Hillier, D., Wendl, M. C., and Green, P. 1998. Base-calling of automated sequencer traces using Phred. I. Accuracy assessment. Genome Res. 8:175-185.

Fedorova, M., van de Mortel, J., Matsumoto, P. A., Cho, J., Town, C. D., VandenBosch, K. A., Gantt, J. S., and Vance C. P. 2002. Genome-wide identification of nodule-specific transcripts in the model legume Medicago truncatula. Plant Physiol. 130:519-537.
Franken, P., and Requena, N. 2001 Analysis of gene expression in arbuscular mycorrhiza: new approaches and challenges. New Phytol. 150:431-439.

Franken, P., Requena, N., Buetehorn, B., Krajinski, F., Kuhn, G., Lapopin, L., Mann, P., Rhody, D., and Stommel, M. 2000. Molecular Analysis of the arbuscular mycorrhiza symbiosis. Arch. Acker Pflanzenbau. Bodenkd. 45:271-286.

Gattiker, A., Basteiges, E., Bairoch, A. 2002. ScanProfile: A reference implementation of a PROSITE scanning tool. Appl. Bioinformatics 1:101108.

George, E., Haeussler, K., Vetterlein, D., Gorgus, E., and Marschner, H. 1992. Water and nutrient translocation by hyphae of Glomus mosseae. Can. J. Bot. 70:2130-2137.

Giovanetti, M., Avio, L., Sbrana, C., and Citernesi, A. S. 1993. Factors affecting appressorium development in the vesicular-arbuscular mycorrhizal fungus Glomus mosseae (Nicol. \& Gerd.) Gerd. \& Trappe. New Phytol. 123:115-122.

Greene, E. A., Erard, M., Dedieu, A., and Barker, D. G. 1998. MtENOD16 and 20 are members of a family of phytocyanin-related early nodulins. Plant Mol. Biol. 36:775-783.

Hammond-Kosack, K. E., and Jones, J. D. 1996. Resistance gene-dependent plant defence responses. Plant Cell 8:1773-1791.

Handberg, K., and Stougaard, J. 1992. Lotus japonicus, an autogamous, diploid legume species for classical and molecular genetics. Plant $\mathbf{J}$. 2:487-496

Harrison, M. J. 1996. A sugar transporter from Medicago truncatulaaltered expression pattern in roots during vesicular-arbuscular (VA) mycorrhizal associations. Plant J. 9:491-503.

Harrison, M. J. 1999. Molecular and cellular aspects of the arbuscular mycorrhizal symbiosis. Annu. Rev. Plant Physiol. Plant Mol. Biol. 50:361389.

Harrison, M. J., Dewbre, G. R., and Liu, J. 2002. A phosphate transporter from Medicago truncatula involved in the acquisition of phosphate released by arbuscular mycorrhizal fungi. Plant Cell 14:2413-2429.

Hildebrandt, U., Schmelzer, E., and Bothe, H. 2002. Expression of nitrate transporter genes in tomato colonized by an arbuscular mycorrhizal fungus. Physiol. Plant 115:125-136.

Hirsch, A. M., Brill, L. M., Lim, P. O., Scambray, J., and van Rhijn, P. 1995. Steps toward defining the role of lectins in nodule development in legumes. Symbiosis 19:155-173.

Jeanmougin, F., Thompson, J. D., Gouy, M., Higgins, D. G., and Gibson, T. J. 1998. Multiple sequence alignment with Clustal X. Trends Biochem. Sci. 23:403-405.

Jefferson, R. A., Kavanagh, T. A., and Bevan, M. V. 1987. GUS fusions: $\beta$ glucoronidaseas a sensitive and versatile gene fusion marker in higher plants. EMBO (Eur. Mol. Biol. Organ.) J. 6:3901-3907.

Jiménez-Zurdo, J. L., Frugier, F., Crespi, M. D., and Kondorosi, A. 2000. Expression profiles of 22 novel markers for organogenetic pathways acting in alfalfa nodule development. Mol. Plant-Microbe Interact. 13:96-106.

Johansen, A., Jakobsen, I., and Jensen, E. S. 1992. Hyphal transport of ${ }^{15} \mathrm{~N}$-labeled nitrogen by a vesicular-arbuscular mycorrhiza fungus and its effect on depletion of inorganic soil N. New Phytol. 122:281-288.

Journet, E. P., van Tuinen, D., Gouzy, J., Crespeau, H., Carreau, V., Farmer, M. J., Niebel, A., Schiex, T., Jaillon, O., Chatagnier, O., Godiard, L., Micheli, F., Kahn, D., Gianinazzi-Pearson, V., and Gamas, P. 2002. Exploring root symbiotic programs in the model legume Medicago truncatula using EST analysis. Nucleic Acids Res. 30:5579-5592.

Krajinski, F., Hause, B., Gianinazzi-Pearson, V., and Franken, P. 2002 Mtha1, a plasma membrane H+-ATPase gene from Medicago truncatula, shows arbuscule-specific induced expression in mycorrhizal roots. Plant Biol. 4:754-761.

Küster, H., Hohnjec, N., Krajinski, F., El Yahyaoui, F., Manthey, K., Gouzy, J., Dondrup, M., Meyer, F., Kalinowski, J., Brechenmacher, L., van Tuinen, D., Gianinazzi-Pearson, V., Pühler, A., Gamas, P., and Becker, A. 2004. Construction and validation of comprehensive cDNAbased macro- and microarrays to explore root endosymbioses in the model legume Medicago truncatula. J. Biotechnol. 108:95-113.

Liang, F., Holt, I., Pertea, G., Karamycheva, S., Salzberg, S. L., and Quackenbush, J. 2000. An optimized protocol for analysis of EST sequences. Nucleic Acids Res. 28:3657-3665.

Liu, H., Trieu, A. T., Blaylock, L. A., and Harrison, M. J. 1998. Cloning and characterization of two phosphate transporters from Medicago truncatula roots-regulation in response to phosphate and to colonization by arbuscular mycorrhizal (AM) fungi. Mol. Plant-Microbe Interact. $11: 14-22$

Liu, J., Blaylock L. A., Endre G., Cho, J., Town, C. T., VandenBosch K A., and Harrison M. J. 2003. Transcript profiling coupled with spatial expression analyses reveals genes involved in distinct developmental stages of an arbuscular mycorrhizal symbiosis. Plant Cell 15:2106-2123. 
Manthey, K., Krajinski, F., Hohnjec, N., Firnhaber, C., Pühler, A., Perlick, A. M., and Küster, H. 2004. Transcriptome profiling in root nodules and arbuscular mycorrhiza identifies a collection of novel genes induced during Medicago truncatula root endosymbioses. Mol. Plant-Microbe Interact. 17:1063-1077.

Mitra, R. M., and Long, S. R. 2004. Plant and bacterial mutants define three transcriptionally distinct stages in the development of the Medicago truncatula/Sinorhizobium meliloti symbiosis. Plant Physiol. 134:1-10.

Nagahshi, G., and Douds, D. D., Jr. 1997. Appressorium formation by AM fungi on isolated cell walls of carrot roots. New Phytol. 136:299-304.

Nakai, K., and Kanehisa, M. 1992. A knowledge base for predicting protein localization sites in eukaryotic cells. Genomics 14:897-911.

Newsham, K. K., Fitter, A. H., Watkinson, A. R. 1995. Arbuscular mycorrhiza protect an annual grass from root pathogen fungi in the field. J. Ecol. 83:991-1000.

Paszkowski, U., Kroken, S., Roux, C., and Brigg, S. P. 2002. Rice phosphate transporters include an evolutionarily divergent gene specifically activated in arbuscular mycorrhizal symbiosis. Proc. Natl. Acad. Sci. U.S.A. 99:13324-13329.

Peumans, W. J., and van Damme, E. J. M. 1995. Lectins as plant defence proteins. Plant Physiol. 109:347-352.

Quackenbush, J., Liang, F., Holt, I., Pertea, G., and Upton, J. 2000. The TIGR gene indices: reconstruction and representation of expressed gene sequences. Nucleic Acids Res. 28:141-145.

Quandt, H. J., Puehler, A., and Broer, I. 1993. Transgenic root nodules of Vicia hirsuta: A fast and efficient system for the study of gene expression in indeterminate-type nodules. Mol. Plant-Microbe Interact. 6:699-706.

Rausch, C., Daram, P., Brunner, S., Jansa, J., Laloi, M., Leggewie, G., Amrhein, N., and Bucher, M. 2001. A phosphate transporter expressed in arbuscule-containing cells in potato. Nature 414:462-470.

Salzer, P., Bonanomi, A., Beyer, K., Vogeli-Lange, R., Aeschbacher, R. A., Lange, J., Wiemken, A., Kim, D., Cook, D. R., and Boller, T. 2000. Differential expression of eight chitinase genes in Medicago truncatula roots during mycorrhiza formation, nodulation, and pathogen infection. Mol. Plant-Microbe Interact. 13:763-777.

Schüssler, A., Schwarzott, D., and Walker, C. 2001. A new fungal phylum, the Glomeromycota: phylogeny and evolution. Mycol. Res. 105:14131421

Sigrist, C. J., Cerutti, L., Hulo, N., Gattiker, A., Falquet, L., Pagni, M., Bairoch, A., and Bucher, P. 2002. PROSITE: a documented database using patterns and profiles as motif descriptors. Brief Bioinform. 3:265274

Slezack, S., Dumas-Gaudot, E., Paynot, M., and Gianinazzi, S. 2000. Is a fully established arbuscular mycorrhizal symbiosis required for a bioprotection of Pisum sativum roots against Aphanomyces euteiches? Mol. Plant-Microbe Interact. 13:238-241

Stekel, D. J., Git, Y., and Falciani, F. 2000. The comparison of gene expression from multiple cDNA libraries. Genome Res. 10:2055-2061.
Szabados, L., Charrier, B., Kondorosi, A., de Bruijn, F. J., and Ratet, P. 1995. New plant promoter and enhancer testing vectors. Mol. Breed. 1:419-423.

Trouvelot, A., Kough, J. L., and Gianinazzi-Pearson, V. 1986. Mesure du taux de mycorhization VA d'un système radiculaire. Recherche des méthodes d'estimation ayant une signification fonctionnelle. Pages 217 221 in: The Mycorrhizae: Physiology and Genetics. V. GianinazziPearson and S. Gianinazzi, eds.INRA Presse, Paris.

VandenBosch, K., and Stacey, G. 2003. Advances in legume biology. Plant Physiol. 131:839-839.

VandenBosch, K. A., Rodger, L. R., Sherrier, D. J., and Kishinevsky, B. D. 1994. A peanut nodule lectin in infected cells and in vacuoles and the extracellular matrix of nodule parenchyma. Plant Physiol. 104:327-337.

van Rhijn, P., Goldberg, R. B., and Hirsch, A. M. 1998. Lotus corniculatus nodulation specificity is changed by the presence of a soybean lectin gene. Plant Cell 10:1233-1250.

Vieweg, M. F., Frühling, M., Quandt, H.-J., Heim, U., Bäumlein, H., Pühler, A., Küster, H.. and Perlick, A. M. 2004. The promoter of the Vicia faba L. leghemoglobin gene VfLb29 is specifically activated in the infected cells of root nodules and in the arbuscule-containing cells of mycorrhizal roots from different legume and non-legume plants. Mol. Plant-Microbe Interact. 17:62-69.

Wang, W., Peumans, W. J., Rouge, P., Rossi, C., Proost, P., Chen, J., and van Damme, E. J. M. 2003. Leaves of the Lamiacea species Glechoma hederacea (ground ivy) contain a lectin that is structurally and evolutionary related to legume lectins. Plant J. 33:293-304.

Wulf, A., Manthey, K., Doll, J., Perlick, A. M., Linke, B., Bekel, T., Meyer F., Franken, P., Küster, H., and Krajinski, F. 2003. Transcriptional changes in response to arbuscular mycorrhiza development in the model plant Medicago truncatula. Mol. Plant-Microbe Interact. 16:306-314.

Zhu, H., Cannon, S. B., Young, N. D., and Cook, D. R. 2002. Phylogeny and genomic organization of the TIR and non-tIR NBS-LRR resistance gene family in Medicago truncatula. Mol. Plant-Microbe Interact. 15:529-539.

\section{AUTHOR-RECOMMENDED INTERNET RESOURCES}

European Bioinformatics Institute EMBnet ClustalW server: www.ebi.ac.uk/clustalw

ExPASy PROSITE database: www. expasy.ch

The Institute for Genomic Research (TIGR) M. truncatula gene index: www.tigr.org/tdb/mtgi

The Medicago truncatula Genome Sequencing Project, Advanced Center for Genome Technology of the University of Oklahoma and the Noble Foundation: www.genome.ou.edu/medicago.html

National Center for Biotechnology Information Blast2X sever: www.ncbi.nlm.nih.gov/BLAST

PSORT protein sorting predication tool: psort.nibb.ac.jp

The University of California-Davis Medicago truncatula physical and genetic map BAC sequences: mtgenome.ucdavis.edu/index.html 